\title{
Overexpression of Galectin-7, A Myoepithelial Cell Marker, Enhances Spontaneous Metastasis of Breast Cancer Cells
}

Mélanie Demers, ${ }^{\star}$ April A.N. Rose, ${ }^{\dagger}$

Andrée-Anne Grosset, ${ }^{\ddagger}$ Katherine Biron-Pain, ${ }^{*}$ Louis Gaboury, ${ }^{\ddagger}$ Peter M. Siegel, ${ }^{\dagger}$ and Yves St-Pierre*

From the Institut national de la recherche scientifique-Institut Armand-Frappier," Laval, Québec; the Goodman Cancer Centre, McGill University, Montreal, Québec; and the Institut de Recherche en Immunologie et Cancérologie, ${ }^{\neq}$Montreal, Québec, Canada

Galectins are members of a family of $\boldsymbol{\beta}$-galactosidesbinding proteins that have recently emerged as novel modulators in different aspects of cancer. The expression of galectins in tumors and/or the tissue surrounding them has been well documented. Since galectin-7 expression has been associated with epithelial tissues and varies significantly in various types of cancer, we have investigated for the first time its role in breast cancer. Using two preclinical mouse models, high levels of galectin-7 expression in breast cancer cells drastically increased their ability to metastasize to lungs and bones. Significant increases in the number of pulmonary metastases and osteolytic lesions were induced by overexpression of galectin- 7 compared with control cells. In human tissues, galectin-7 was specifically found in myoepithelial cells of normal human breast tissue, but not in luminal cells. Its expression was severely altered in breast carcinoma, many samples showing greater than $70 \%$ of galectin-7 positive cells. High expression levels of galectin-7 were restricted to high-grade breast carcinomas, including HER2 overexpressing and basal-like groups. In HER2 overexpressing cases, galectin-7 expression was associated with lymph node axillary metastasis. Taken together, our results indicate that galectin-7 may represent a potential target for both specific detection and therapeutic inhibition of metastatic breast cancer. (Am J Pathol 2010, 176:3023-3031; DOI: 10.2353/ajpath.2010.090876)
Members of the galectin family share a unique carbohydrate recognition domain that confers specificity for $\beta$-galactoside derivatives. Based on structural features, the 15 mammalian galectins known to date have been classified as proto, chimera, or tandem repeat types. Numbered according to the order of their discovery, galectins 1, 2, 5, 7, $10,11,13,14$, and 15 are of the prototype; galectins $4,6,8$, 9 , and 12 are of the tandem repeat type; and galectin 3 is the only galectin of the chimera type. ${ }^{1}$ Most galectins are nonglycosylated soluble proteins that can be found both intracellularly (cytoplasm and/or nucleus) and extracellularly depending on the cell type, cell cycle stage, and differentiation state. Accordingly, galectins have been implicated in a wide range of cellular functions, including embryonic development, wound healing, apoptosis, intercellular adhesion, cell migration, immune response, and cancer. ${ }^{2}$

Galectin-7 was initially described as a marker that reflected the differentiation status of keratinocytes. ${ }^{3,4}$ Functionally, its intracellular form has been associated with UVB-induced apoptosis in epidermis since sunburn/ apoptotic keratinocytes express abnormally high levels of galectin-7. ${ }^{5}$ Early studies suggested that galectin-7 might function as an apoptosis regulator when it was identified as 1 of 14 transcripts induced in colorectal cancer cells undergoing p53-dependent apoptosis. ${ }^{6}$ Additional studies have since confirmed that galectin-7

Supported by grants to Y.S.P. from the Canadian Institute for Health Research (grant number MOP-89697) and P.M.S. from the Canadian Breast Cancer Research Alliance (grant number MOP-84386). M.D., K.B.P., and A.A.N.R. were supported by studentships from the Fond de la Recherche en Santé du Québec. P.M.S. is a research scientist of the Canadian Cancer Society.

Accepted for publication February 18, 2010

CME Disclosure: None of the authors disclosed any relevant financial relationships.

Supplemental material for this article can be found on http://ajp. amjpathol.org.

Current address for M.D.: Immune Disease Institute, Harvard Medical School, Boston, MA

Address reprint requests to Yves St-Pierre, Ph.D., INRS-Institut Armand-Frappier, 531 Blvd Des Prairies, Laval, Québec, Canada, H7V 1 B7 E-mail: yves.st-pierre@iaf.inrs.ca. 
can render tumor cells more susceptible to apoptotic stimuli ${ }^{7,8}$; although others have also shown that extracellular binding of galectin-7 to cell surface receptors can trigger signals that reduce neuroblastoma cell growth without the appearance of features characteristic of classical apoptosis. ${ }^{9}$

Given its pro-apoptotic role, galectin-7 might be expected to aid in the elimination of tumor cells. However, in sharp contrast to such negative roles played by galectin-7 in tumor development, Lu et $\mathrm{al}^{10}$ have previously found that galectin-7 is overexpressed in chemicallyinduced mammary carcinomas. They reported that galectin-7 expression was restricted to mammary carcinomas and was not detected in any other normal tissues examined in the adult rat, providing the first indication that galectin-7 could be associated with tumor progression. Rorive et $\mathrm{al}^{11}$ later observed that galectin-7 expression was markedly higher in different forms of papillary carcinomas than in benign thyroid tumors. Recent work in lymphoma further supported the idea that galectin-7 may promote tumorigenesis. Mice injected with Iymphoma cells ectopically expressing galectin-7 constitutively developed large metastatic tumors in the liver and kidneys with massive infiltration of tumor cells in the parenchyma. ${ }^{12}$ In contrast, only a few scattered foci of tumor cells with limited infiltration were observed in mice injected with control lymphoma cells. Suppression of galectin-7-expression by using specific antisense approaches significantly delayed metastasis of lymphoma cells. ${ }^{13}$ Taken together, these results have uncovered a novel functional role for galectin-7: its ability to promote tumor progression.

To investigate the role of galectin-7 in breast cancer, we have examined its expression in normal and malignant human breast tissues to determine whether galectin-7 was associated with any particular subtype, or biological or clinical feature. Together, our data indicate that galectin-7 is expressed in aggressive phenotype of breast carcinomas and is a critical determinant in spontaneous metastasis of lung and bone-homing breast tumor cells. This suggests that galectin- 7 is not only a potentially novel therapeutic target in the treatment of breast cancer metastasis, but may also prove to be a valuable marker to monitor disease progression.

\section{Materials and Methods}

\section{Cell Lines and Reagents}

Immortalized human keratinocytes ( $\mathrm{HaCaT}$ ) were a kind gift of Dr. Thierry Magnaldo (Génétique et physiopathologie des cancers épidermiques, FRE3086 IGMRC CNRS, Faculté de Médecine, Université de Nice). MCF-7 and MDA-MB-231 cells lines were maintained in Dulbecco's modified Eagle's medium complete medium (supplemented with $8 \%[\mathrm{v} / \mathrm{v}]$ fetal calf serum, $2 \mathrm{mmol} / \mathrm{L}$ L-glutamine, $10 \mathrm{mmol} / \mathrm{L}$ HEPES buffer, and for $1 \mathrm{mmol} / \mathrm{L}$ Sodium Pyruvate for MCF-7). The 4T1 and 66c14 cell lines were maintained in Dulbecco's modified Eagle's medium (supplemented with $8 \%$ [v/v] FCS, 2 mmol/L L-glutamine, and $10 \mathrm{mmol} / \mathrm{L}$ HEPES buffer). All cell culture products were purchased from Life Technologies (Burlington, ON, Canada). All other reagents were purchased from Sigma (St. Louis, MO), unless otherwise indicated.

\section{Generation of Stable Transfectants Expressing Galectin-7}

To obtain stable 4T1 and 66c14 breast carcinoma transfectants expressing galectin-7, the cDNA encoding the murine galectin- $7^{12}$ was cloned in Sr $\alpha$ eukaryotic expression vector (kindly provided by Dr. François Denis) by using Spel and Notl restriction enzymes. Controls were generated by using 4T1 and 66c14 breast carcinoma cells transfected with the empty $\operatorname{Sr} \alpha$ vector. Transfection was performed by using Lipofectamine 2000 according to the manufacturer's instructions (Invitrogen Canada, Inc., Burlington, ON). After 48 hours of culture, transfected cells were allowed to grow in complete medium containing $8 \mu \mathrm{g} / \mathrm{ml}$ of puromycin. Individual colonies were expanded, PCR analysis was performed on genomic DNA for assessing vector insertion, and galectin-7 expression was monitored by Western blot analysis.

\section{Western Blot Analysis}

Cells were homogenized and resuspended in lysis buffer (10 mmol/L Tris, $\mathrm{pH} \mathrm{7.5,} \mathrm{2.5 \%} \mathrm{Triton} \mathrm{X-100)} \mathrm{containing}$ protease inhibitors (Roche, Laval, QC, Canada). Equal amounts of whole-cell (50 $\mu \mathrm{g})$ extracts were separated on SDS-polyacrylamide gel electrophoresis gel and transferred onto nitrocellulose membranes (Bio-Rad Laboratories, Mississauga, ON, Canada). The membranes were first blocked with $10 \%$ milk in PBS/0.5\% Tween 20 overnight and subsequently blotted for 2 hours with a goat anti-mouse galectin-7 polyclonal antibody (1: 1000; R\&D Systems Minneapolis, MN), a rabbit antiPoly-(ADP-ribose) polymerase (PARP)-1 (p25) polyclonal antibody (1:1000; Epitomics, Burlingame, CA), or mouse anti- $\beta$-actin antibodies. Secondary antibodies consisted of horseradish peroxydase-conjugated donkey anti-rabbit or anti-mouse IgG (Sigma). Detection was performed by the enhanced chemiluminescence method (Amersham Baie d'Urfé, QC, Canada).

\section{RNA Isolation and RT-PCR}

Total RNA was isolated by using Trizol reagent according to the manufacturer's protocol (Invitrogen). Briefly, total RNA $(2 \mu \mathrm{g})$ was reverse transcribed by using the OmniScript reverse transcriptase (Qiagen, Mississauga, ON, Canada), and PCR was amplified by using the following conditions: $94^{\circ} \mathrm{C}$ for 1 minute, $62^{\circ} \mathrm{C}$ for 1 minute, and $72^{\circ} \mathrm{C}$ for 1 minute followed by a final extension step at $72^{\circ} \mathrm{C}$ for 10 minutes. The primers used for PCR amplification were the following: human $\mathrm{mmp}-9$, 5'-CAACATCACCTATTGGATCC-3' (sense) and 5'-CGGGTGTAGAGTCTCTCGCT-3' (antisense); for $\beta$-actin 5'-CATGGATGACGATATCGCTGCGC-3' (sense) and 
(5'-GCTGTCGCCACGCTCGGTCAGGAT-3' (antisense); human galectin-7, 5'-ACCAACCCGGTCCCAG-3' (sense) and 5'-GCGGGCTAACGCTTTATTTGC-3' (antisense); mouse galectin-7, 5' - CCATGTCTGCTACCCATCAC-3' (sense) and 5'-GCTTAGAAGATATTCAATGAATGC-3' (antisense); and glyceraldehyde-3-phosphate dehydrogenase, 5'-CGGAGTCAACGGATTTGGTCGTAT-3' (sense) and 5'-AGCCTTCTCCATGGTGGTGAAGAC-3' (antisense). Thirty or 35 cycles of amplification were performed in a thermal cycler (model PTC-100 TM, MJ Research, Watertown, MA). Each assay was repeated three times to verify the accuracy of the results. Thirty or 35 cycles of ampPCR assays using equal amounts of RNAs that were reverse-transcribed and amplified by PCR for 25 to 40 cycles with gene-specific primers confirmed that the amplification was in the linear range for each gene. As an internal control, amplification of $\beta$-actin or glyceraldehyde3-phosphate dehydrogenase mRNA was performed by RT-PCR using specific primers. Amplified products were analyzed by electrophoresis on $1 \%$ agarose gels by using ethidium bromide staining and UV illumination. Loading was equalized to the internal control mRNA.

\section{Metastasis Assays}

Female BALB/c mice (4 to 8 weeks old) were purchased from Charles River Laboratories (St-Constant, QC, Canada). The mice were housed in facilities managed by the Institut national de la recherche scientifique (INRS) Experimental Biology Center or the McGill University Animal Resources Centre (Montreal, QC, Canada). All animal experiments were conducted under an INRS- or McGill University-approved Animal Use Protocol in accordance with guidelines established by the Canadian Council on Animal Care. For experimental metastasis assays using the $66 \mathrm{c} 14$ model, $10^{5}$ vector control or Galectin-7 expressing 66cl4 cells were resuspended in $100 \mu \mathrm{l}$ PBS and injected into the left cardiac ventricle of 4- to 5-week-old BALB/c mice as previously described. ${ }^{14}$ A total of nine mice were injected with vector control, and 13 animals were injected with galectin-7 expressing $66 \mathrm{cl} 4$ breast cancer cells. All mice were sacrificed when the first mouse appeared cachectic at 13 days postinjection. For the 4T1 model, the procedure was performed as described $^{15}$ with minor modifications. Briefly, female BALB/c mice, aged 6 to 8 weeks, were injected with vector control or stable transfectants expressing galectin-7 tumor into the mammary fat pad. The size of the primary tumors was monitored twice a week, and the number of metastatic nodules on the lung was evaluated by histological examination at necropsy.

\section{Quantification of Osteolytic Lesions}

Immediately before sacrifice, mice were anesthetized, and digital X-rays were obtained with a Faxitron Specimen Radiography System (model MX-20 digital, Faxitron X-Ray LLC, Toronto, ON, Canada). At the termination of these experiments, all digital $\mathrm{X}$-rays were blinded and scored by two independent researchers. Each X-ray was examined for the presence of osteolytic lesions in the following six sites: proximal humerus, distal femur, and proximal tibia (left and right side). The number of mice possessing at least one osteolytic lesion was divided by the total number of animals in each cohort to determine the percentage of mice developing bone metastases. At the time of necropsy, hind limbs from three and four mice injected with vector control or galectin-7 stable transfectants, respectively, were removed and fixed in $4 \%$ paraformaldehyde. Fixed tissues were paraffin embedded, sectioned, stained with H\&E. Routine histology services were provided by the Centre for Bone and Periodontal Research (McGill University) histology platform. For each cohort, 12 H\&E stained bone (femur or tibia) sections were scanned with an Aperio slide scanner (Aperio Technologies, Inc., Vista, CA) at $20 \times$ magnification. Total bone area and metastatic lesion area were quantified by using Aperio ImageScope software (version 9.1.19). The

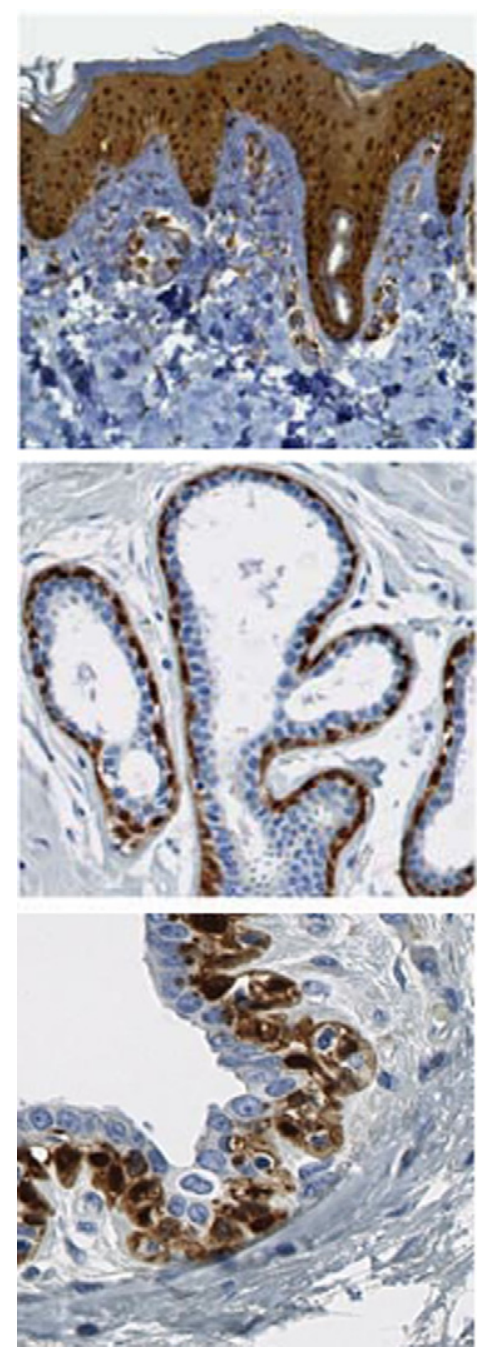

Figure 1. Galectin-7 expression in normal mammary myoepithelial cells. Immunohistological analysis of human normal tissues showing expression of galectin-7 in the stratified epithelium of the skin (upper panel) and in mammary tissues showing specific expression in myoepithelial cells (central and lower panels). Note the presence of intense galectin-7 protein immunoreactivity in the mammary myoepithelial cells and its absence in the lumens of normal ducts and adjacent stroma. Strong galectin-7 cytoplasmic and nuclear protein staining was found in myoepithelial cells. 
metastatic lesion area was expressed as a percentage of the total tissue area.

\section{Immunohistocytochemistry}

Paraffin-embedded sections were deparaffinized in $x y$ lenes and rehydrated through a graded alcohol series. Antigen retrieval was performed for 10 minutes in 1 $\mathrm{mmol} / \mathrm{L}$ EDTA ( $\mathrm{pH} 8.0$ ), preheated to $95^{\circ} \mathrm{C}$ to $100^{\circ} \mathrm{C}$ in a steamer. Tissue sections were blocked in $1 \%$ bovine serum albumin and $5 \% \mathrm{~N}$-hydroxysuccinimide in $1 \times \mathrm{PBS}$ and incubated overnight at $4^{\circ} \mathrm{C}$ with a mouse anti-human galectin-7 monoclonal antibody (R\&D Systems). This antibody shows an identical pattern of expression with previously raised rabbit anti-human galectin-7 polyclonal antibody generated by Magnaldo and colleagues ${ }^{4,12}$ when tested against various tissue sections, including human mammary tissues. For instance, although both antibodies react against the skin epithelium and the mammary myoepithelial cells, they do not react against skeletal muscle
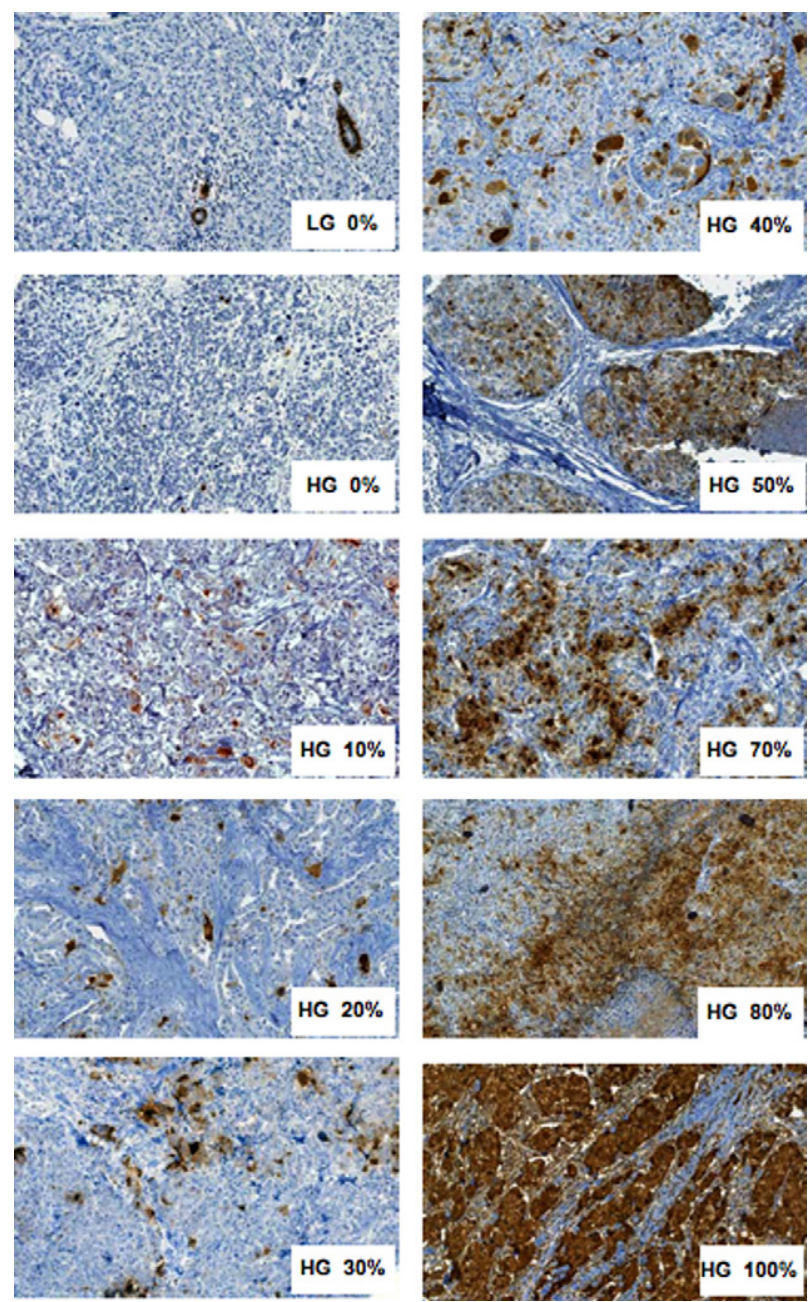

Figure 2. Galectin-7 expression in human breast carcinomas. Scoring of tissue microarrays constructed from human breast carcinomas specimens were stained (3,3'-diaminobezidine, brown) with anti-galectin-7 antibody. Specimens were scored for percentages of galectin-7-positive cells by IHC of paraffin-embedded tissue in low grade (LG) and high grade (HG) carcinoma. The absence of a signal was scored as " $0 . "$ and the thyroid gland. The specificity of the antibody for galectin-7 has also been validated by the manufacturer, which reports less than $0.5 \%$ cross-reactivity with human gal-1, gal-3, gal-4, and gal-8. For double staining of tissue sections, reactions for galectin-7 and GATA-3 were performed by using the Discovery XT automated immunostainer (Ventana Medical Systems, Tucson, AZ) on

Table 1. Histoclinical Correlations of Breast Cancers According to Galectin-7 Expression

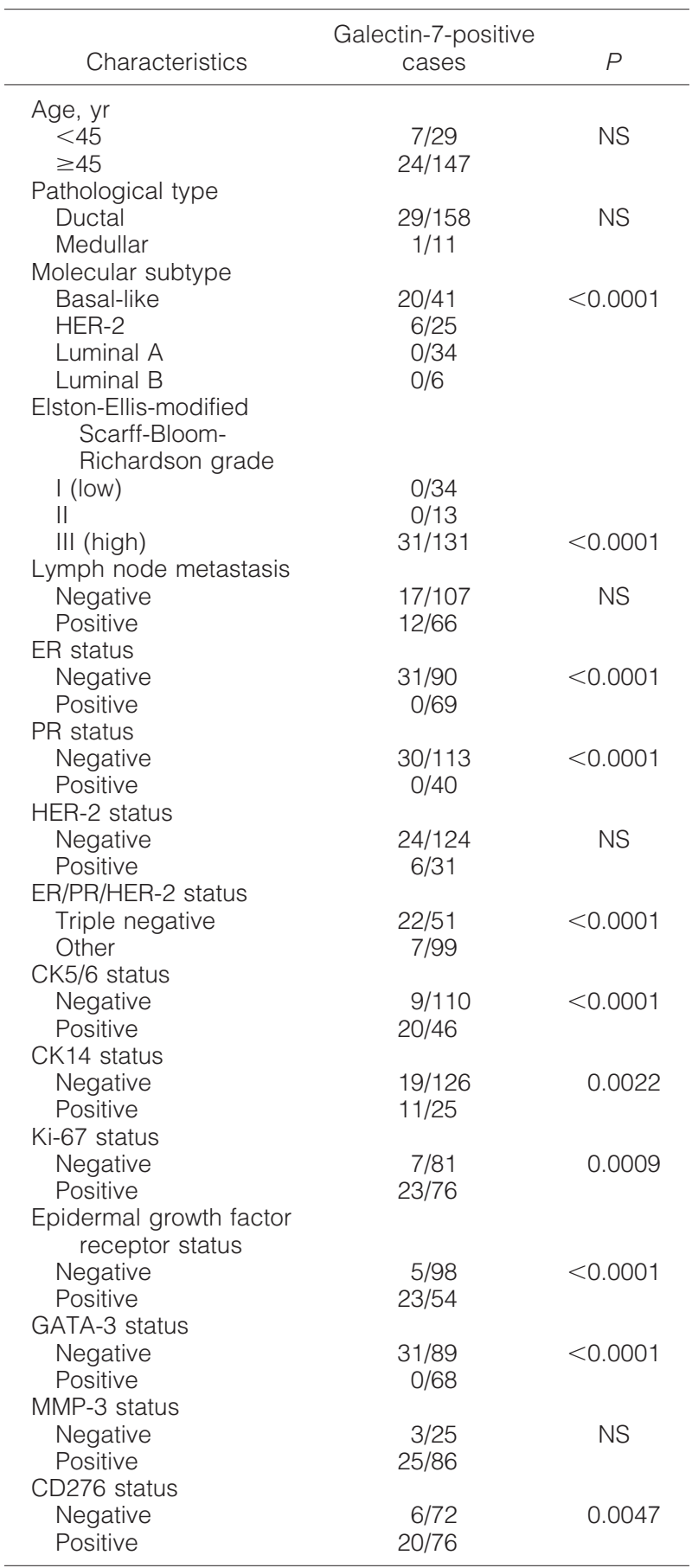

To assess differences in clinicopathologic features between the two groups of patients, Fisher's exact test was used for qualitative variables with discrete categories. 
deparaffinized sections incubated in EDTA buffer $(\mathrm{pH} 8)$ for antigen retrieval. The anti-human galectin-7 antibody and an anti-GATA-3 HG3-31 monoclonal antibody (Santa Cruz Biotechnology, Santa Cruz, CA) were used at 1:50 and 1:250 dilutions, respectively, for 60 minutes. To reveal the reaction, DABmap (brown) and REDmap (red) kits were used (Ventana Medical Systems), and the slides were counterstained with hematoxylin. Each section was scanned at a high resolution (Nanozoomer, Hammamatsu Photonics K.K.).

\section{Patients and Tumor Materials}

A cohort of 213 patients diagnosed with primary breast cancer between 2003 and 2008 at the Centre Hospitalier de l'Université de Montréal was used for the study. Tumors were selected on the basis of the histological diagnosis according to the classification of Nottingham modified by Elston and Ellis. ${ }^{16}$ The cohort consisted of both low-grade and high-grade ductal carcinomas and of medullary carcinomas (typical and atypical). Estrogen receptor (ER) $\alpha$ status was positive in all low-grade carcinomas. The study was approved by the research ethics committee of the research center at the Centre Hospitalier de l'Université de Montréal.

\section{Tissue Microarrays and Immunohistochemistry}

Formalin-fixed paraffin-embedded material from each primary tumor sample was used to construct tissue microarrays with an automated arrayer design to construct high-density tissue microarray blocks (ATA-27 Beecher Instruments, Sun Prairie, WI). To that end, triplicate $1 \mathrm{~mm}$ cores from each tumor and control tissues were punched out and arrayed into six recipient blocks. For immunohistochemical analysis, $3-\mu \mathrm{m}$ thick sections were prepared from each tissue microarray. Immunostaining reactions for galectin-7 were performed by using the Discovery XT automated immunostainer (Ventana Medical Systems). Deparaffinized sections were incubated in cell conditioning 1 ( $\mathrm{pH}$ 8.0) for antigen retrieval and then stained for 60 minutes with the anti-human galectin-7 monoclonal antibody using a 1:150 dilution. The slides were counterstained with hematoxylin and bicarbonate. Each section was scanned at a high resolution by using the Nanozoomer Digital Pathology (Hamamatsu, Bridgewater, NJ).

\section{Results}

\section{Galectin-7 Expression in Human Breast Tissues}

To date, there have been no published descriptions of galectin-7 protein expression and localization in normal breast tissue and breast cancer. Specimens from normal regions of human mammary glands were stained by immunohistochemistry (IHC) with anti-galectin-7 antibody. Initial staining with control skin sections showed extensive staining of stratified epithelium, consistent with previous studies reporting that galectin-7 is considered a marker of stratified epithelia. ${ }^{3,4} \mathrm{IHC}$ staining of normal breast tissues showed that cytoplasm and nuclei of human myoepithelial cells but not luminal epithelial cells were positive for galectin-7 (Figure 1). The expression of galectin-7 was representative of pre- and postmenaupausic individuals (aged between 44 and 49 years old). Additional IHC studies in samples from younger individuals showed a similar pattern of expression (Supplemental Figure S1, see http://ajp.amjpathol.org).

To examine the expression of galectin-7 in human mammary tumors, paraffin-embedded tissue sections were selected from patients with breast cancer to construct tissue microarrays and immunostained with an antihuman galectin-7 monoclonal antibody. We found that galectin-7 expression was severely altered in breast carcinoma tissues (Figure 2). The range of percentage positive cells varied greatly among samples. Elevated expression of galectin-7 was restricted to high-grade breast carcinomas $(P<0.001$; Table 1$)$. None of the low-grade carcinoma samples expressed galectin-7. Galectin-7positive cases were mostly associated with a basal-like phenotype $(P<0.0001)$. On all galectin-7-positive cases found, all were ER and progesterone-receptornegative. Six cases were HER2 positive. This association with basal-like tumors was further demonstrated by positive correlations between galectin-7 and "basal" keratins, such as CK-5/6 $(P<0.0001)$. All cases were negative for GATA-3 $(P<0.0001)$, a defining marker of the luminal subtype. ${ }^{17}$ Interestingly, all HER2/galectin-7-

Table 2. Histoclinical Correlations of Her2-Positive Breast Cancer According to Galectin-7 Expression

\begin{tabular}{|c|c|c|c|c|}
\hline Characteristics & HER-2 ${ }^{-}$/gal- $7^{+}(n=24)$ & $P$ & $\mathrm{HER}-2^{+} / \mathrm{gal}-7^{+}(n=6)$ & $P$ \\
\hline \multicolumn{5}{|l|}{ Age, yr } \\
\hline$<45$ & $6 / 29$ & NS & $1 / 29$ & NS \\
\hline$\geq 45$ & $18 / 146$ & & $5 / 146$ & \\
\hline \multicolumn{5}{|l|}{ LN metastasis } \\
\hline Negative & $17 / 107$ & NS & 0/107 & 0.0066 \\
\hline Positive & $6 / 65$ & & $5 / 65$ & \\
\hline \multicolumn{5}{|l|}{ GATA-3 status } \\
\hline Negative & $24 / 88$ & $<0.0001$ & $6 / 88$ & 0.0359 \\
\hline Positive & $0 / 68$ & & $0 / 68$ & \\
\hline \multicolumn{5}{|c|}{ Epidermal growth factor receptor status } \\
\hline Negative & 3/98 & $<0.0001$ & $2 / 98$ & 0.0359 \\
\hline Positive & $19 / 54$ & & $4 / 54$ & \\
\hline
\end{tabular}

The LN status for two patients was not available. 
A

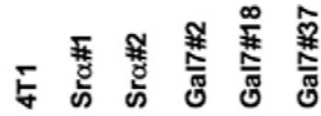

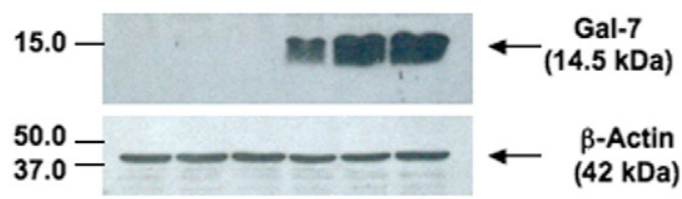

B

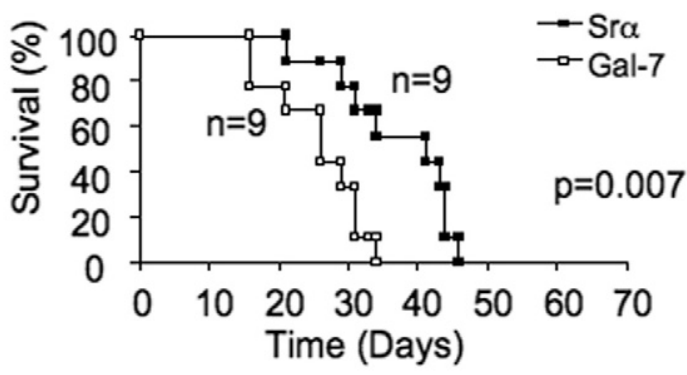

C
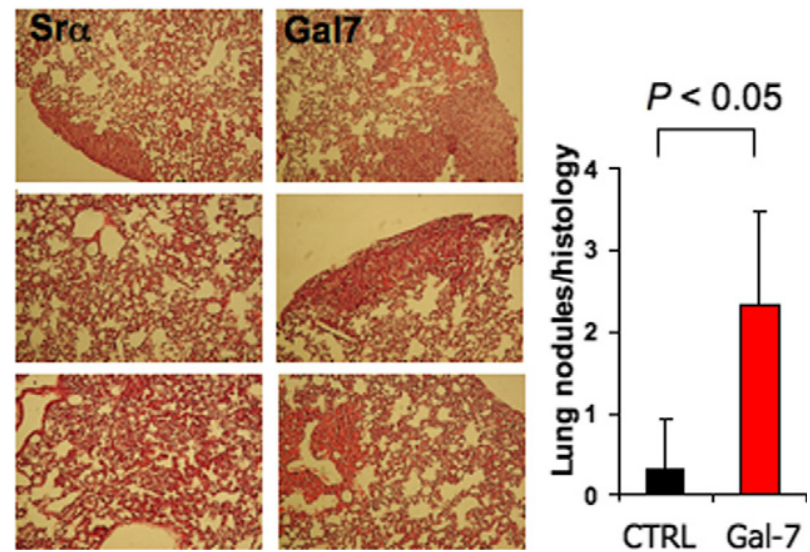

Figure 3. Effect of galectin-7 expression on lung metastasis induced by 4T1 cells. A: $4 \mathrm{~T} 1$ cells were transfected with the Sr $\alpha$ /puro expression vector containing the murine galectin-7 cDNA and stable transfectants (Gal7\#2, Gal7\#18, and Gal7\#37) constitutively expressing galectin-7 were obtained. The levels of endogenous and overexpressed galectin-7 protein were determined by Western blotting. $\beta$-actin was used as a loading control. The expression of galectin-7 in transfectants was not decreased on long-term in vitro culture of the clones but was nevertheless always assessed by Western blot analysis before their in vivo testing. Control transfectants $(\operatorname{Sr} \alpha)$ included 4T1 cells transfected with the $\operatorname{Sr} \alpha$ /puro expression vector without cDNA insert. B: Survival analysis of syngeneic BALB/C mice injected into the mammary fat pad with transfectants (open box) or controls (filled box). C: At necropsy, lungs were harvested and fixed in 10\% formalin for histological examination to study the effect of galectin-7 on $4 \mathrm{~T} 1$ tumor cells that spontaneously metastasize into the lung.

positive were also positive for lymph node metastasis $(P=0.0066$; Table 2$)$, supporting the hypothesis that galectin-7 may have a role in metastatic breast cancer.

\section{Galectin-7 Overexpression Increases Lung and Bone Metastasis}

To examine the role of galectin-7 in breast cancer metastasis, the $4 \mathrm{~T} 1$ and the $66 \mathrm{c} 14$ breast cancer models were used. The 4T1 line metastasizes to the lungs after inoculation into the mammary gland while $66 \mathrm{cl} 4$ cells

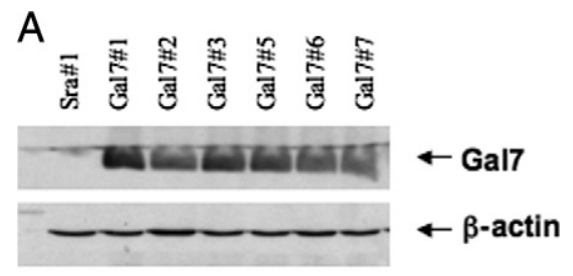

B

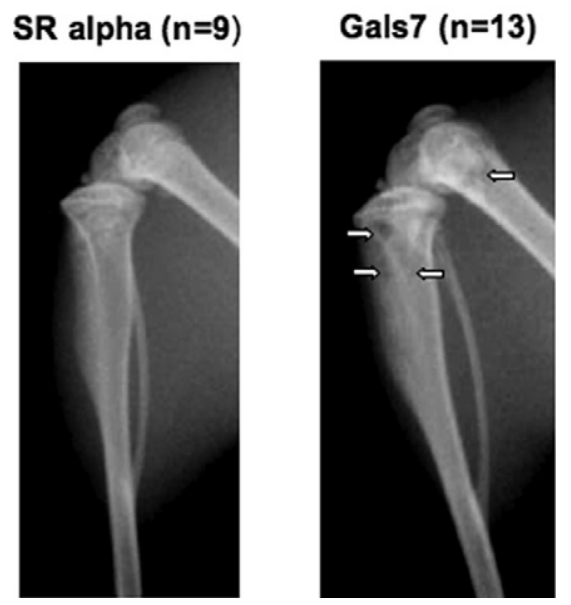

Figure 4. Galectin-7 expression promotes bone metastasis of $66 \mathrm{cl} 4$ breast cancer cells after cardiac injection. A: 66c14 breast carcinoma cells were transfected with the $\operatorname{Sr} \alpha$ /puro expression vector containing the murine galectin-7 cDNA, and stable transfectants constitutively expressing galectin-7 were obtained and tested for galectin-7 by Western blot analyses. Control transfectants $(\operatorname{Sr} \alpha)$ also included 66c14 cells transfected with the $\operatorname{Sr} \alpha /$ puro expression vector without cDNA insert. B: X-ray images of tibiae derived from $\mathrm{BALB} / \mathrm{c}$ mice injected into the left cardiac ventricle with either 66cl4 control cells containing an empty vector (left panel, 66cl4/vector control) or two independent clones expressing Galectin-7 (right panel, 66cl4/Galectin7). Arrows indicate regions of bone destruction.

spontaneously metastasize to the lung, but not to bone when injected into the arterial system via the left ventricle. ${ }^{18}$ All these lines were derived from the same spontaneous mammary carcinoma in a BALB/c/C3H mouse. ${ }^{19}$ A series of stable transfectants overexpressing galectin-7 was first generated in 4T1 cells along with control transfectants derived from 4T1 cells transfected with an empty vector (Figure 3A). The cells were then assessed for their ability to spontaneously metastasize after injection in the mammary fat pad in syngeneic BALB/c mice. No significant difference in the growth rate or the final tumor

Table 3. Quantification of Bone Metastases after Cardiac Injection of $66 \mathrm{cl} 4$ Cells

\begin{tabular}{|c|c|c|c|}
\hline Construct & $\begin{array}{l}\text { Mice }^{\star} \text { with } \\
\text { bone } \\
\text { metastases } \\
\text { (x-ray), \% }\end{array}$ & $\begin{array}{l}\text { Bones with } \\
\text { metastases } \\
(\mathrm{H} \& \mathrm{E}), \%\end{array}$ & $\begin{array}{c}\text { Lesion area/ } \\
\text { tissue } \\
(\mathrm{H \& E}), \%\end{array}$ \\
\hline $\mathrm{pSR} \alpha /$ Empty & 0.0 & 50.0 & 12.1 \\
\hline $\mathrm{pSR} \alpha / \mathrm{Gal}-7$ & 53.8 & 100.0 & 48.5 \\
\hline$P$ & $0.01^{\S}$ & $0.01^{\S}$ & $<0.0001^{\pi}$ \\
\hline
\end{tabular}

${ }^{*} \mathrm{pSR} \alpha / \operatorname{Empty}(n=9) ; \mathrm{pSR} \alpha / \mathrm{Gal}-7(n=13)$.

†Multiple bone samples were taken from individual mice; pSR $\alpha /$ empty ( $n=3$ mice; $n=12$ bones); pSR $\alpha /$ Gal-7 ( $n=4$ mice; $n=12$ bones).

FIncludes only those bones with metastatic lesions.

§Fisher's exact test (two tails).

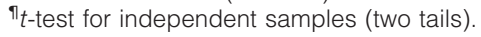



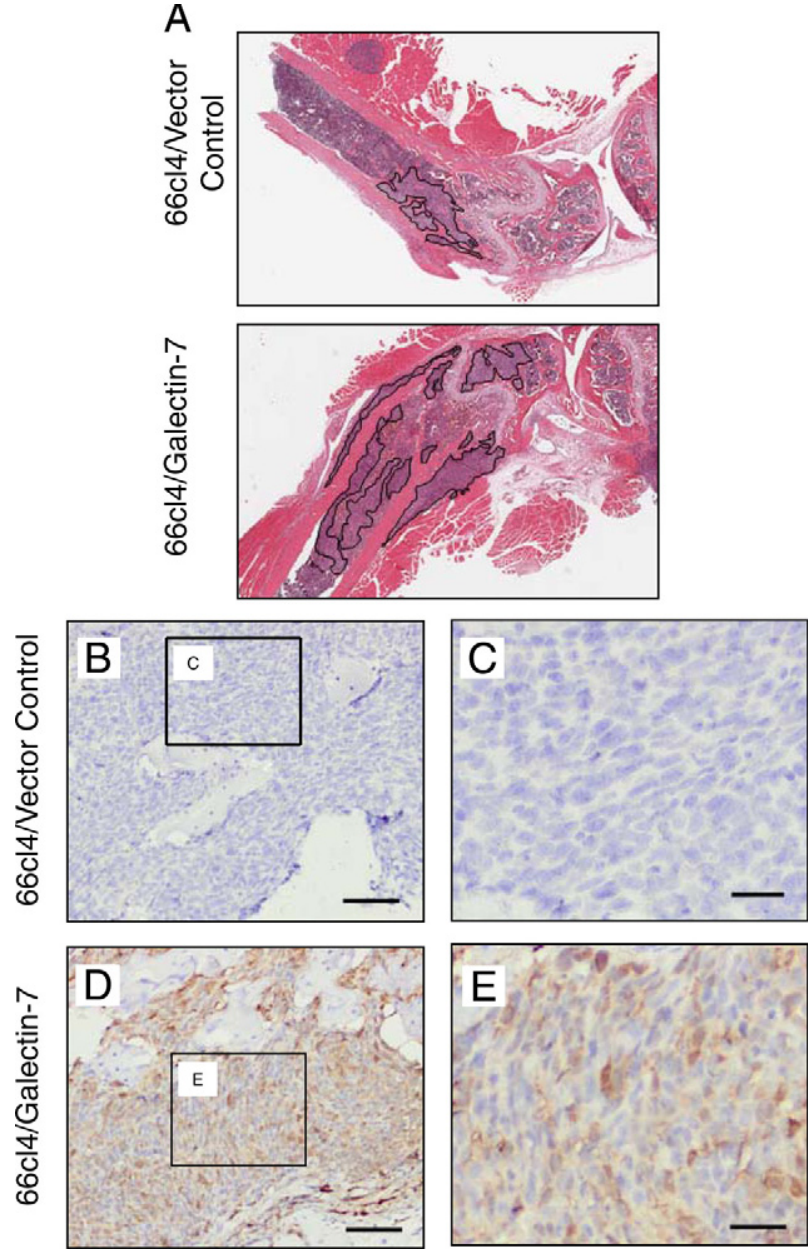

Figure 5. Immunohistological analyses of bone metastases induced by $66 \mathrm{c} 14$ transfectants. A: H\&E stained images revealing the proximal tibia of an animal injected with $66 \mathrm{cl} 4 \mathrm{SR} \alpha$ cells harboring an empty vector (upper panel, 66cl4/vector control) or 66cl4Gal7 expressing galectin-7 (lower panel, 66cl4/Galectin-7). Outlined regions indicate areas of 66cl4-derived lesions growing in the bone. B-E: Immunohistochemical staining for Galectin-7 in lesions resulting from 66cl4/Vector control cells (B and C) and 66cl4/Galectin-7 (D and E) breast cancer cells. The open boxes found in $\mathbf{C}$ and $\mathbf{D}$ indicate regions that are shown at higher magnification in panels $\mathbf{B}$ and D. Scales bars $=75 \mu \mathrm{mol} / \mathrm{L}(\mathbf{B}$ and $\mathbf{D}) ; 25 \mu \mathrm{mol} / \mathrm{L}(\mathbf{C}$ and $\mathbf{E})$.

weight at the completion of the experiment was found between control transfectants or those expressing galectin-7 (data not shown). Similarly, there was no difference between the proliferation rates of $\operatorname{Sr} \alpha$ control cells and

A
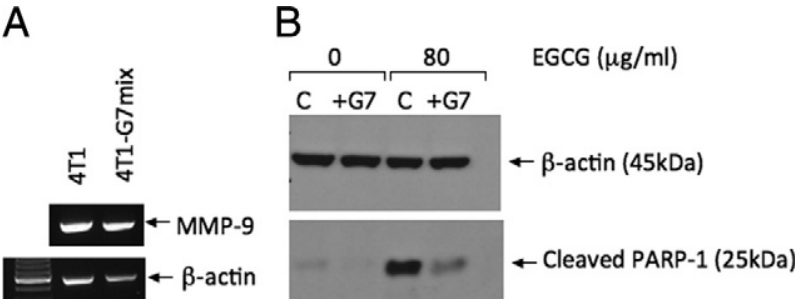

Figure 6. Expression of MMP-9 and PARP-1 cleavage in 4T1 cells expressing galectin-7. A: Expression of $m m p-9$ in $4 \mathrm{~T} 1$ control cells (transfected with the control vector) and from cells (a mix of three transfectants expressing galectin-7 [G7]). B: Western blot analysis of PARP-1 cleavage in control 4T1 cells or $4 \mathrm{~T} 1$ cells transfected with $\mathrm{G} 7$ after overnight exposure to $80 \mathrm{mg} / \mathrm{ml}$ of (-)-epigallocatechin galatte. $\beta$-actin was used as a loading control. $\mathrm{C}$, control $4 \mathrm{~T} 1$ cells.
4T1 cells expressing galectin-7 cells in vitro, although galectin-7 expression was stable in transfectants for the duration of the experiments (data not shown), suggesting that galectin-7 did not alter tumor growth at the primary site. We found, however, that galectin-7 accelerated the development of metastases to lung, as the mean survival time of the mice injected with galectin-7 transfectants was significantly shorter than that of mice injected with controls ( $25.7 \pm 6.5$ days vs. $37 \pm 8.5$ days, respectively; $P=0.007$; Figure 3B). Detailed histopathological analysis showed that $4 \mathrm{~T} 1$ cells expressing galectin-7 developed significantly more metastatic foci in the lungs (Figure $3 \mathrm{C}$ ). In contrast only few scattered foci of tumor cells were observed in mice injected with control cells.

Because osteolytic lesions contribute to breast cancer associated morbidity, ${ }^{20}$ the relationship between galectin-7 expression and bone metastasis was studied by using the $66 \mathrm{c} 14$ variant. A series of transfectants expressing high levels of galectin-7 (66c14Gal7) and control cells $(66 c 14 S r \alpha)$ were thus generated as in the case of $4 \mathrm{~T} 1$ cells after transfection and selection by puromycin resistance and tested by Western blot analysis (Figure $4 \mathrm{~A}$ ). We had indeed found that aggressive variants of $66 \mathrm{c} 14$ breast cancer cells isolated from the bone marrow overexpressed galectin-7 as compared with poorly metastatic cells and their parental cells (Supplemental Figure S2, see http://ajp.amjpathol.org) ${ }^{7,15}$ As in the case of 4T1 cells, no significant difference in the growth rate or the final tumor weight at the completion of the experiment was found between control transfectants or those expressing galectin-7 (data not shown), confirming that galectin-7 did not alter tumor growth at the primary site. Examination of macroscopic lesions in mice injected with $66 \mathrm{cl} 4 \mathrm{Sr} \alpha$ showed that galectin-7 expression in $66 \mathrm{c} 14$ significantly enhanced their capacity to metastasize to the bone $(P<0.01$; Figure 4B and Table 3). Histological examination of sections of tibia and femoral bones of mice showed a significant increase in the frequency of bone lesions induced by 66c14Gal7 cells as compared with control 66c14Sr $\alpha$ cells (Table 3). Moreover, the osteolytic lesions were significantly $(P<0.001)$ larger with $66 \mathrm{c} 14 \mathrm{Gal} 7$ cells than those induced by $66 \mathrm{c} 14 \mathrm{SR} \alpha$ cells, further emphasizing the protumorigenic potential of galectin-7 (Figure 5A and Table 3). IHC staining confirmed the expression of galectin-7 in metastatic lesions derived from 66c14Gal7 stable transfectants and a lack thereof in control cells (Figure 5, B-E).

The dissemination of breast cancer cells at distant sites is dictated by the emergence of tumor cells with increased invasive behavior associated with increased expression of members of the matrix metalloproteinase family, such as $m m p-9$. Because our previous studies in lymphomas had shown that galectin-7 increased the expression of $m m p-9$, we have examined the level of $m m p-9$ in nonaggressive parental cells and its aggressive varinats overexpressing galectin-7. We found, however, that both the 4T1 parental cells and the 4T1 transfectants expressed similar levels of $\mathrm{mmp}-9$ (Figure 6 , A and B). Similar results were obtained with $66 \mathrm{c} 14$ (data not shown). Because other members of the galectin family increase the metastatic behavior by conferring protection 
from apoptosis, ${ }^{21,22}$ we have thus examined whether galectin-7 can protect from apoptosis. Our result showed that galectin-7 protects $4 \mathrm{~T} 1$ cells from apoptosis induced after exposure of (-)-epigallocatechin galatte, a pharmacological agent known to induce apoptosis in $4 \mathrm{~T} 1 \mathrm{cells}^{23}$

\section{Discussion}

Galectin-7 is primarily found in stratified epithelia, especially in epidermis. It was identified as a stratified epithelial marker following searches for epidermal genes responsive to retinoic acid and for genes that were down-regulated in actively dividing keratinocytes. Its expression in human breast cancer tissues and its possible role in breast cancer metastasis have never been investigated to date. In the present work, we provide evidence that it plays a pivotal role in controlling the metastatic behavior of breast cancer cells while its expression is associated with aggressive subtypes of breast carcinomas.

Using anti-galectin-7 specific monoclonal antibody on tissue microarrays constructed from samples obtained from normal breast tissues and breast carcinomas, we found that galectin-7 is specifically expressed at the protein level in mammary myoepithelial cells in tissues of normal individuals. These results are consistent with microarray studies from normal breast luminal and myoepithelial cells identifying galectin-7 as the first gene on the list among the 42 most predictive genes that distinguish luminal epithelial cells from myoepithelial cells. ${ }^{24,25} \mathrm{Ga}$ lectin-7 expression is thus very distinct from that of galectin-3, a member of the galectin family associated in breast cancer expressed in normal luminal epithelial but not myoepithelial cells. ${ }^{24}$ Moreover, in contrast to galectin-7, acquisition of an invasive phenotype via galectin-3 is associated with a decreased expression of this galactoside-binding lectin rather than an increased expression as we observed in the case of galectin- 7.26

Apart from the results of Lu et al, ${ }^{10}$ who showed that galectin-7 was expressed in rat mammary tissues after chemically-induced mammary tumorigenesis, the first indication that galectin-7 might be expressed in human breast cancer was reported in the genomic profiling data from Perou et al, ${ }^{27}$ who provided a molecular portrait of 65 surgical specimens obtained from 42 individuals. Their microarray data revealed that although galectin-7 transcripts were expressed at very low levels in normal breast tissues, they were highly expressed in cell lines with a basal-like phenotype. Here, we extended these results by showing that galectin-7 was expressed at the protein level and was highly expressed in basal-like breast cancer cells with an ER/PR negative status and expressing basal keratins $5 / 6$ and epidermal growth factor receptor. The association between galectin-7 and progression of breast cancer is further supported by the correlation between galectin-7 and high tumor grade and the fact that all HER-2-positive tumors are also positive for lymph node metastasis. This increase of galectin-7 expression in mammary epithelial cells is most likely modulated at the transcriptional level and possibly involve epigenetic mechanisms, such as DNA methylation ${ }^{28,29}$ (Supplemental Figures S2 and S3, see http://ajp.amjpathol.org). ${ }^{7,15}$ Finally, we found an inverse relationship between overexpression of galectin- 7 and absence of GATA-3, a transcription factor known to suppress tumor dissemination of breast cancer. ${ }^{30}$ Whether the emergence of a GATA-3-negative/galectin-7-positive population is distinctively aggressive during tumor progression is a likely possibility. Indeed, constitutive galectin-7 expression by gene transfer approaches in cell lines that express low or undetectable level of galectin-7 resulted in an increased metastatic behavior to the lung and bone and larger osteolytic lesions.

Our preliminary attempts to determine the exact mechanism(s) used by galectin-7 to increase the invasive behavior using in vitro migration assays have not permitted to conclude that galectin- 7 increases the invasive behavior of breast cancer cells. We indeed found that both 4T1 and $66 \mathrm{c} 14$ cells already express constitutive levels of $m m p-9$, which are not affected by transfection with galectin-7. We rather believe that lower survival rates and increased metastases in mice injected with breast cancer cells overexpressing galectin- 7 are related to the ability of galectin-7 to protect from apoptosis, as previously shown in the case of galectin-3. ${ }^{31,32}$ This hypothesis is supported by our results showing that expression of galectin-7 in breast cancer cells inhibits PARP-1 cleavage (Figure 6B). The ability of galectin-7 to render mammary cells more resistant to apoptosis is also reminiscent with in vivo data in keratinocytes from galectin-7-deficient mice. ${ }^{33}$ Like galectin-3, galectin-7 contains a highly conserved XWGR motif corresponding to the $\mathrm{BH} 1$ domain of $\mathrm{Bcl}-2$ and mutation of WGR $\rightarrow$ WAR motif in the $\alpha$ helix of $\mathrm{BCl}-2$ and has been shown to disrupt $\mathrm{BCl}-2$ anti-apoptotic function. ${ }^{34}$ Because this motif has been shown to be responsible for binding to nucleic acid, a role for galectin-7 in the nucleus would be consistent with its strong nuclear staining we observed in breast cancer cells. This mechanism would be consistent with our statistically significant correlation between galectin-7 and Ki-67. Further studies regarding the role of galectin-7 in resistance to apoptosis is currently under investigation.

\section{Acknowledgments}

We thank Diane Tremblay for her excellent technical support, Dr. François Denis for providing the Sr $\alpha$ vector, and Dr. Edouard F. Potworowski for a critical reading of the article.

\section{References}

1. Elola MT, Wolfenstein-Todel C, Troncoso MF, Vasta GR, Rabinovich GA: Galectins: matricellular glycan-binding proteins linking cell adhesion, migration, and survival. Cell Mol Life Sci 2007, 64:1679-1700

2. Liu FT, Rabinovich GA: Galectins as modulators of tumor progression. Nat Rev Cancer 2005, 5:29-41

3. Madsen P, Rasmussen HH, Flint T, Gromov P, Kruse TA, Honoré B Vorum H, Celis JE: Cloning, expression, and chromosome mapping of human galectin-7. J Biol Chem 1995, 270:5823-5829

4. Magnaldo T, Bernerd F, Darmon M: Galectin-7, a human 14-kDa 
S-lectin, specifically expressed in keratinocytes and sensitive to retinoic acid. Dev Biol 1995, 168:259-271

5. Bernerd F, Sarasin A, Magnaldo T: Galectin-7 overexpression is associated with the apoptotic process in UVB-induced sunburn keratinocytes. Proc Natl Acad Sci USA 1999, 96:11329-11334

6. Polyak K, Xia Y, Zweier JL, Kinzler KW, Vogelstein B: A model for p53-induced apoptosis. Nature 1997, 389:300-305

7. Kuwabara I, Kuwabara Y, Yang RY, Schuler M, Green DR, Zuraw BL, Hsu DK, Liu FT: Galectin-7 (PIG1) exhibits pro-apoptotic function through JNK activation and mitochondrial cytochrome $\mathrm{c}$ release. J Biol Chem 2002, 277:3487-3497

8. Ueda S, Kuwabara I, Liu FT: Suppression of tumor growth by galectin-7 gene transfer. Cancer Res 2004, 64:5672-5676

9. Kopitz J, André S, von Reitzenstein C, Versluis K, Kaltner H, Pieters RJ, Wasano K, Kuwabara I, Liu FT, Cantz M, Heck AJ, Gabius HJ: Homodimeric galectin-7 (p53-induced gene 1) is a negative growth regulator for human neuroblastoma cells. Oncogene 2003 , 22:6277-6288

10. Lu J, Pei H, Kaeck M, Thompson HJ: Gene expression changes associated with chemically induced rat mammary carcinogenesis. Mol Carcinog 1997, 20:204-215

11. Rorive S, Eddafali B, Fernandez S, Decaestecker C, André S, Kaltner H, Kuwabara I, Liu FT, Gabius HJ, Kiss R, Salmon I: Changes in galectin-7 and cytokeratin-19 expression during the progression of malignancy in thyroid tumors: diagnostic and biological implications. Mod Pathol 1997, 15:1294-1301

12. Demers M, Magnaldo T, St-Pierre Y: A novel function for galectin-7: promoting tumorigenesis by up-regulating MMP-9 gene expression. Cancer Res 2005, 65:5205-5210

13. Demers M, Biron-Pain K, Hébert J, Lamarre A, Magnaldo T, St-Pierre Y: Galectin-7 in lymphoma: elevated expression in human lymphoid malignancies and decreased lymphoma dissemination by antisense strategies in experimental model. Cancer Res 2007, 67:2824-2829

14. Rose AA, Pepin F, Russo C, Abou Khalil JE, Hallett M, Siegel PM: Osteoactivin promotes breast cancer metastasis to bone. Mol Cancer Res 2007, 5:1001-1014

15. Kang Y, Siegel PM, Shu W, Drobnjak M, Kakonen SM, Cordón-Cardo C, Guise TA, Massagué J: A multigenic program mediating breast cancer metastasis to bone. Cancer Cell 2003, 3:537-549

16. Elston CW, Ellis IO: Pathological prognostic factors in breast cancer: I. The value of histological grade in breast cancer: experience from a large study with long-term follow up. Histopathology 1991, 19:403410

17. Wilson BJ, Giguère V: Meta-analysis of human cancer microarrays reveals GATA3 is integral to the estrogen receptor alpha pathway. Mol Cancer 2008, 7:49

18. Eckhardt BL, Parker BS, van Laar RK, Restall CM, Natoli AL, Tavaria MD, Stanley KL, Sloan EK, Moseley JM, Anderson RL: Genomic analysis of a spontaneous model of breast cancer metastasis to bone reveals a role for the extracellular matrix. Mol Cancer Res 2005, $3: 1-13$

19. Aslakson CJ, Miller FR: Selective events in the metastatic process defined by analysis of the sequential dissemination of subpopulations of a mouse mammary tumor. Cancer Res 1992, 52:1399-1405

20. Mundy GR: Metastasis to bone: causes, consequences and therapeutic opportunities. Nat Rev Cancer 2002, 2:584-593

21. Akahani S, Nangia-Makker P, Inohara H, Kim H-RC, Raz A Galectin-3: a novel antiapoptotic molecule with a functional $\mathrm{BH} 1$ (NWGR) domain of Bcl-2 family. Cancer Res 1997, 57:5272-5276

22. Yu F, Finley RL, Raz A, and Kim H-RC: Galectin-3 translocates to the perinuclear membranes and inhibits cytochrome $\mathrm{c}$ release from the mitochondria. J Biol Chem 2002, 277:15819-15827

23. Baliga MS, Meleth S, Katiyar SK: Growth inhibitory and antimetastatic effect of green tea polyphenols on metastasis-specific mouse mammary carcinoma $4 \mathrm{~T} 1$ cells in vitro and in vivo systems. Clin Cancer Res 2005, 11:1918-1927

24. Jones C, Mackay A, Grigoriadis A, Cossu A, Reis-Filho JS, Fulford L, Dexter T, Davies S, Bulmer K, Ford E, Parry S, Budroni M, Palmieri G, Neville AM, O'Hare MJ, Lakhani SR: Expression profiling of purified normal human luminal and myoepithelial breast cells: identification of novel prognostic markers for breast cancer. Cancer Res 2004, 64:3037-3045

25. Chung $\mathrm{CH}$, Bernard PS, Perou CM: Molecular portraits and the family tree of cancer. Nat Genet 2002, 32:533-540

26. Castronovo V, Van Den Brule FA, Jackers P, Clause N, Liu FT, Gillet C, Sobel ME: Decreased expression of galectin-3 is associated with progression of human breast cancer. J Pathol 1996, 179:43-48

27. Perou CM, Sørlie T, Eisen MB, van de Rijn M, Jeffrey SS, Rees CA, Vam de Rijn M, Jeffrey SS, Rees CA, Pollack JR, Ross DT, Joh sen $\mathrm{H}$ Akslen LA, Fluge O, Pergamenschikow A, Willieams C, Zhu SX, Lonning PE, Borresen-Dale AL, Brown PO, Bolstein D: Molecular portraits of human breast tumours. Nature 2000, 406:747-752

28. Demers M, Couillard J, Giglia-Mari G, Magnaldo T, St-Pierre Y: Increased galectin-7 gene expression in lymphoma cells is under the control of DNA methylation. Biochem Biophys Res Commun 2009, 387:425-429

29. Chiariotti L, Salvatore P, Frunzio R, Bruni CB: Galectin genes: regulation of expression. Glycoconj J 2004, 19:441-449

30. Kouros-Mehr H, Bechis SK, Slorach EM, Littlepage LE, Egeblad M, Ewald AJ, Ewald AJ, Pai SY, Ho IC, Werb Z: GATA-3 links tumor differentiation and dissemination in a luminal breast cancer model. Cancer Cell 2008, 13:141-152

31. Nakahara S, Oka N, Raz A: On the role of galectin-3 in cancer apoptosis. Apoptosis 2005, 10:267-275

32. Lin $\mathrm{Cl}$, Whang EE, Abramson MA, Donner DB, Bertagnolli MM, Moore FD Jr, Ruan DT: Galectin-3 regulates apoptosis and doxorubicin chemoresistance in papillary thyroid cancer cells. Biochem Biophys Res Commun 2009, 379:626-631

33. Gendronneau G, Sidhu SS, Delacour D, Dang T, Calonne C, Houzelstein D, Magnaldo T, Poirier F: Galectin-7 in the control of epidermal homeostasis after injury. Mol Biol Cell 2008, 19:5541-5549

34. Yin XM, Oltvai ZN, Korsmeyer SJ: $\mathrm{BH} 1$ and $\mathrm{BH} 2$ domains of $\mathrm{Bcl}-2$ are required for inhibition of apoptosis and heterodimerization with Bax. Nature 1994, 369:321-323 